\title{
The DiSCmap Project: Overview and First Results
}

\author{
Duncan Birrell $^{1}$, Milena Dobreva ${ }^{1,3}$, Gordon Dunsire ${ }^{1}$, \\ Jillian Griffiths ${ }^{2}$, Richard Hartley ${ }^{2}$, and Kathleen Menzies ${ }^{1}$ \\ ${ }^{1}$ Centre for Digital Library Research (CDLR), Information Resources Directorate (IRD), \\ University of Strathclyde, Livingstone Tower, 26 Richmond Street Glasgow, \\ G1 1XH United Kingdom \\ \{duncan.birrell, milena.dobreva, g.dunsire\}strath.ac.uk, \\ klmenzies@cis.srtath.ac.uk \\ ${ }^{2}$ Centre for Research in Library and Information Management (CERLIM), \\ Department of Information and Communications, Manchester Metropolitan University, \\ Geoffrey Manton Building, Manchester M15 6LL, United Kingdom \\ \{R.J.Hartley, J.R.Griffiths\} @mmu.ac.uk \\ ${ }^{3}$ Institute of Mathematics and Informatics, bl. 8, Acad. G. Bonchev St., \\ 1113 Sofia, Bulgaria
}

\begin{abstract}
Traditionally, digitisation of cultural and scientific heritage material for use by the scholarly community has been led by supply rather than demand. The DiSCmap project commissioned by JISC in 2008, aimed to study what refocussing of digitisation efforts will suit best the users of digitised materials, especially in the context of the research and teaching in the higher education institutions in the UK. The paper presents some of its initial outcomes based on quantitative and qualitative analysis of 945 special collections nominated for digitisation by intermediary users (librarians, archivist and museum curators), as well as end users' study involving a combination of online survey, focus groups and in-depth interviews. The criteria for prioritising digitisation advanced by intermediaries and end users were analysed and cross-mapped to a range of existing digitisation frameworks. A user-driven prioritisation framework which synthesises the findings of the project is presented.
\end{abstract}

Keywords: selection, appraisal, user-defined criteria, digitization, special collections.

\section{Introduction}

The DiSCmap project (Digitisation of Special Collections: mapping, assessment, prioritisation) was commissioned by JISC $^{1}$ in 2008 to CDLR. The work on the project has been completed between September 2008 and May 2009 by CDLR and CERLIM (The Centre for Research in Library and Information Management) at the Manchester Metropolitan University. The project had as its primary goal to study the user needs in digitised special collections in the higher education institutions in the UK.

\footnotetext{
${ }^{1}$ Joint Information Systems Committee (JISC), http://www.jisc.ac.uk/
} 
Traditionally, digitisation of cultural and scientific heritage material for use by the scholarly community has been led by supply rather than demand. JISC's recent Digitisation Strategy [3], however, makes clear their commitment to re-focussing digitisation efforts to make them most valuable to direct users of digitised materials, including researchers, teachers and students.

The project was constructed as a set of inter-connected tasks aimed at assessing the current landscape of digitisation of special collections from the point of view of the needs of the researcher and teachers within UK higher education institutions. It included the following basic components:

- Mapping and assessing existing digitised special collections in UK higher education institutions;

- Identifying and summarising best practice in digitisation within the public and private sector and both nationally and internationally;

- Preparing an inventory, via interaction with librarians, archivists and museum curators, of collections as-yet not digitised;

- Constructing a framework of criteria for the assessment of the potential value and impact in the digitisation of individual collections;

- Using innovative methods, including social networking and participatory workshops, to engage and talk directly to direct users in order to discern their views on current and future digitisation needs.

\section{First Outcomes from DiSCmap}

DiSCmap collected data on 945 collections nominated for digitisation by intermediary users (librarian, archivists and museum curators) from over half of the 196 higher education institutions in the UK. Over half of the collections (54\%) came from the libraries in higher education institutions, 38\% are archival collections, $7 \%$ are museum collections and $1 \%$ - departmental collections.

The implementation of DiSCmap was organised seeking to make its results:

- Representative (by a fair UK wide regional distribution).

- Non-hierarchical (includes Ancient, Old, Redbrick, Post-Robbins and New/Post-1992 higher education institutions).

- Granular (by surveying both intermediaries and end users).

- Functional (deliver the resources users want and need).

The online survey helped to collect evidence on the reasons for nomination of the various collections and this allows understanding better how intermediary users perceive the impact of digitised collections on research and teaching. In parallel, the project studied the direct users' views on anticipated impact of digitised special collections through a combination of web survey, focus groups and in-depth interviews. The interviews with end users showed a different set of criteria for advancing special collections for digitisation. The nominated criteria by both groups of users were crossmapped and compared with other existing frameworks suggested by a number of projects and previous research publications $[1,2,4-8]$. 


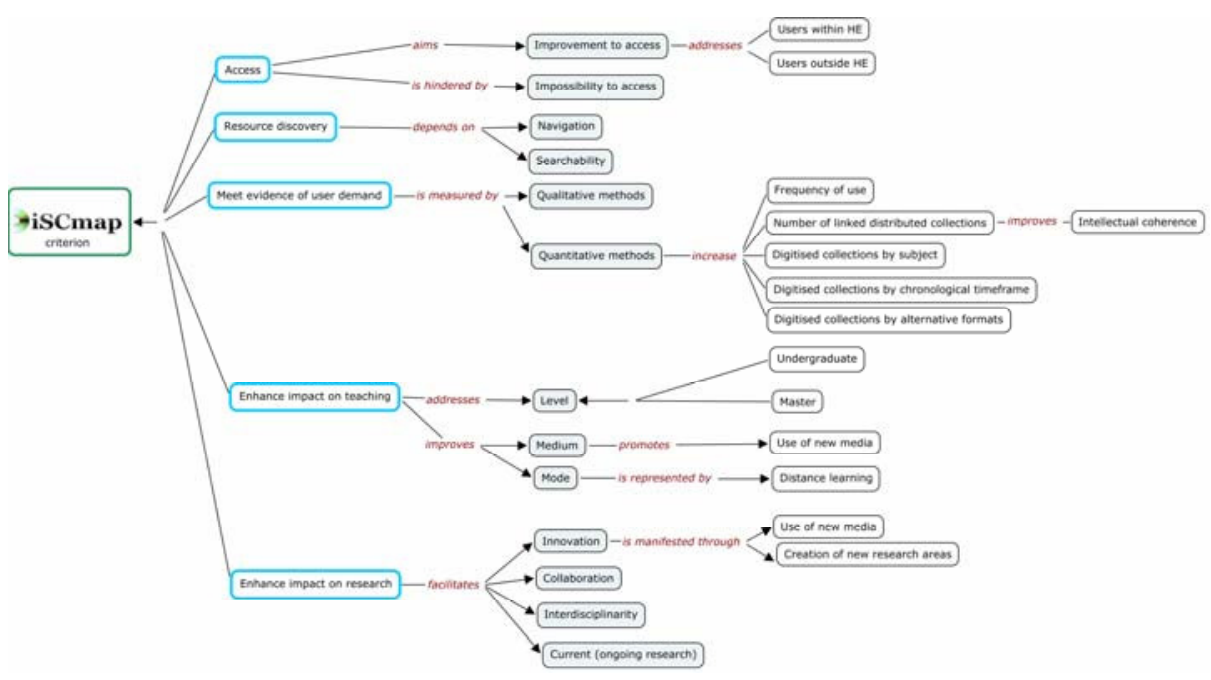

Fig. 1. A concept map of DiSCmap user-driven prioritisation framework

The synthesis of digitisation cases suggested by intermediaries and of the reasons for digitisation by advanced by end users is presented on the concept map below (see Fig. 1).

The distribution of collections across subject domains, regions and types of materials, languages of written materials combined with nominated criteria allows constructing short lists of collections matching different sets of prioritisation criteria. Although the project addressed the needs of higher education institutions in the UK, the comparison of criteria for digitisation with other existing frameworks is of interest to the digital library community. In addition DiSCmap gathered rich evidence on criteria advanced by intermediary and end-users and the differences in their points of view on priorities in digitisation.

\section{Conclusions}

Based on the analysis of the data gathered, the project produced the following recommendations:

1. The long list of collections should be harmonized and sustained into the future.

2. The user-driven framework developed by DiSCmap can be seen as a tool to support a flexible approach to the prioritising digitisation of special collections.

3. A comprehensive collection description and finding utility is needed in the UK.

4. Granularity issues of collection description facilities need to be revisited.

5. Metadata issues for collection level description need to be better addressed.

6. A stronger connection should be established with the actual use of digitised resources in the wider context of research/learning/entertainment. 
7. Information literacy related to resources presenting collections can be further enhanced.

8. Further work can be done on the impact of "to-be" digitised resources (qualitative and quantitative methods).

DiSCmap has analysed a comprehensive range of end user digitisation priorities that are directly related to teaching and research. In doing so it has made considerable advances in identifying and understanding the actual digitisation needs of the scholarly community. It has done so with the aim of removing the element of guesswork and assumption hitherto inherent in our understanding of user requirements in this area. Additionally, its combination of intermediary and end user studies provides a richness of view points which highlight the many important and differing aspects related to the end user dimension in digitisation.

\section{References}

1. Ayris, P.: Guidance for selecting materials for digitisation. In: Joint RLG and NPO Preservation Conference: Guidelines for Digital Imaging, September 28-30, 1998, Warwick, UK, (unpublished) (1998), http: / / eprints.ucl.ac.uk/492/1/paul_ayris3.pdf

2. Cornell University Library. Selecting traditional library materials for digitization. Report of the CUL task force on digitization (2005),

http: / /www. library.cornell.edu/colldev/digitalselection.html

3. JISC digitisation strategy (2008),

http://www.jisc.ac.uk/media/documents/programmes/digitisation /jisc_digitisation_strategy_2008.doc/

4. MINERVA Working Group 6 (2004). Good practices handbook, p.21. DIGIT STAG report (2002), http: / /www.minervaeurope.org/structure/workinggroups / goodpract/document/goodpractices1_3.pdf/

5. National Digital Forum. Digitisation selection work: Position Paper (2007), http://ndf .natlib.govt.nz/downloads/NDF\%20Digitisation\%20Sele ction\%20Work20edited.pdf

6. National Library of Australia Collection digitisation policy (2008), http: / /www.nla.gov.au/policy/digitisation.html

7. Report of the meeting of the digitalization of natural history collections STAG of GBIF (2002), http://circa.gbif.net/Public/irc/gbif/digit/library?l=/ meetings/digit_stag_meeting\&vm=detailed\&sb=Title

8. Ross, S.: Strategies for selecting resources for digitization: source-orientated, user-driven, asset-aware model (SOUDAAM). In: Coppock, T. (ed.) Making information available in digital format: perspectives from practitioners, pp. 5-27. The Stationery Office Ltd., Edinburgh (1999) 